\title{
MULTICHARME: a modified Chernin-type multi-pass cell designed for IR and THz long-path absorption measurements in the CHARME atmospheric simulation chamber
}

\author{
Jean Decker ${ }^{1}$, Éric Fertein ${ }^{1}$, Jonas Bruckhuisen ${ }^{1}$, Nicolas Houzel ${ }^{1}$, Pierre Kulinski ${ }^{1}$, Bo Fang ${ }^{2}$, Weixiong Zhao ${ }^{2}$, \\ Francis Hindle $^{1}$, Guillaume Dhont ${ }^{1}$, Robin Bocquet ${ }^{1}$, Gaël Mouret ${ }^{1}$, Cécile Coeur ${ }^{1}$, and Arnaud Cuisset ${ }^{1}$ \\ ${ }^{1}$ Laboratoire de Physico-Chimie de l'Atmosphère, UR4493, LPCA, \\ Université du Littoral Côte d'Opale, 59140 Dunkerque, France \\ ${ }^{2}$ Laboratory of Atmospheric Physico-Chemistry, Anhui Institute of Optics and Fine Mechanics, HFIPS, \\ Chinese Academy of Sciences, Hefei 230031, Anhui, China
}

Correspondence: Arnaud Cuisset (arnaud.cuisset@univ-littoral.fr)

Received: 25 November 2021 - Discussion started: 1 December 2021

Revised: 13 January 2022 - Accepted: 15 January 2022 - Published: 8 March 2022

\begin{abstract}
We have developed MULTICHARME, a modified Chernin-type multi-pass cell especially designed for IR and $\mathrm{THz}$ long-path absorption measurements in the CHamber for Atmospheric Reactivity and Metrology of the Environment (CHARME). By measuring the output power using a near-IR diode-laser and a $\mathrm{THz}$ amplified multiplication chain, we have established that the effective reflectivity of MULTICHARME is better than $94 \%$ over approximately three decades of frequency. Absorption measurements of $\mathrm{N}_{2} \mathrm{O}$ have been performed by probing highly excited rovibrational transitions in the near-IR and ground state rotational transitions at submillimeter wavelengths. In each case the linearity of the absorbance with the path lengths was verified. Finally, we demonstrate that $\mathrm{THz}$ spectroscopy is able to study the isotopic composition of greenhouse polar gases such as $\mathrm{N}_{2} \mathrm{O}$ and to absolutely quantify stable $\left(\mathrm{N}_{2} \mathrm{O}\right)$ and reactive $\left(\mathrm{O}_{3}\right)$ species at trace levels. At low pressure the ozone concentration was continuously monitored and its decay characterized. The deduced ozone lifetime of $3.4 \pm 0.1 \mathrm{~h}$ is shorter compared with previous measurements performed in CHARME at atmospheric pressure. For the first time, the ability of $\mathrm{THz}$ rotational spectroscopy to monitor, with a very high degree of selectivity, stable and reactive polar compounds at trace level in an atmospheric simulation chamber is demonstrated. However, the sensitivity of the THz monitoring needs to be improved to reach atmospheric trace levels. For this purpose, it is necessary to fully understand the origin
\end{abstract}

of the observed baseline variations caused by the complex multiple standing waves present in MULTICHARME.

\section{Introduction}

Atmospheric simulation chambers (ASC) have been developed to study atmospheric physicochemical processes under controlled conditions. Beside small Teflon bags of a few hundred liters, approximately 35 chambers are currently in operation around the world. All these reactors are equipped with a large variety of instruments dedicated to the monitoring of gases and particles, ranging from commercially available apparatuses to specialized custom-designed set-ups offering in situ measurement of chemical species by optical techniques.

Various spectrometers based on photonic sources from UV to mid-IR have been coupled to different ASC allowing the stable and unstable reactants to be monitored along with the gas and particle phase products involved in key atmospheric reactions (Barnes et al., 1994; Bloss et al., 2005b; Rohrer et al., 2005; Wagner et al., 2006; Ren et al., 2017; Massabò et al., 2018). The identification of critical intermediate species and the time-resolved quantification of kinetic parameters are of upmost importance for atmospheric models. The optical components used to couple the probe beam with the ASC are selected depending on the nature of the light source employed, the detection scheme and the geometry of the reac- 
tor. The trace gas monitoring requirement in an ASC makes it necessary to reach sub-ppm limits of detection (LOD) by maximizing the interaction path length between the light and the probed species. Nowadays, most of the ASCs, using optical spectrometers as analyzers, are equipped with an optical system enabling multiple passes of the probe light back and forth across the ASC, thus increasing the absorption path length and consequently improving the LOD.

For example, several ASCs are coupled to commercially available Fourier transform infrared (FTIR) spectrometers for volatile organic compound (VOC) detection at low resolution $\left(>0.5 \mathrm{~cm}^{-1}\right)$ in the mid-IR (typically $400-$ $4000 \mathrm{~cm}^{-1}$ ) using a White-cell multi-pass mirror configuration reaching several hundreds of meters of interaction path lengths with a broadband black-body IR source (White, 1942). The following ASCs are well known examples in the EUROCHAMP 2020 network (EUROCHAMP 2020, 2021): (i) the $4.2 \mathrm{~m}^{3}$ CESAM chamber in Paris uses a globar source inside a Bruker interferometer with a $192 \mathrm{~m}$ path length White-cell (Wang et al., 2011); (ii) the quartz reactor QUAREC in Wuppertal also employs a White-cell configuration to achieve an optical path length of $484.7 \pm 0.8 \mathrm{~m}$ and is entirely mounted inside the photoreactor for sensitive in situ long path IR absorption monitoring of reactants and products (Barnes et al., 1994); (iii) the EUPHORE photoreactor in Valencia makes it possible to intercompare $1 \mathrm{~cm}^{-1}$ resolution FTIR data $(L=616 \mathrm{~m})$ with differential optical absorption spectroscopy measurements in the 389-469 nm UV range with a dedicated White cell (W-DOAS) which can reach $\mathrm{km}$ path lengths (Bloss et al., 2005a, b).

The highly instrumented reactor for atmospheric chemistry (HIRAC) chamber in Leeds is coupled to a laserinduced fluorescence-fluorescent assay by gas expansion (LIF-FAGE) analyzer and to a multiple pass FTIR system. In contrast to the previous examples of traditional White-type arrangements, the HIRAC team chose a modified multiple pass matrix system developed by Chernin and Barskaya (1991) and Chernin (2001). This solution retains the focal properties of the original White cell and perfectly conserves optical throughput over a range of matrix arrangements. In practice, the Chernin cell is very easy to align and shows very good stability to vibrations, with the FTIR giving good LODs over short acquisition times. For observation times as short as $1 \mathrm{~min}$, LODs below $100 \mathrm{ppbv}$ are obtained for ozone and VOCs, such as acetaldehyde, methane and formaldehyde with the FTIR interferometer coupled to the $128.5 \mathrm{~m}$ Chernin cell (Glowacki et al., 2007b). Finally, the Chernin multi-pass cell optimizes the recirculation of the beam over many focused lines on the field mirrors and minimizes overlapping between adjacent refocusing points, thus facilitating the control of the propagation of more divergent beams over long distances.

Due to the lack of reliable and sufficiently powerful sources and due to the difficulty to control the propagation of more divergent beams over long distances, far-IR/terahertz
(THz) spectrometers have never been used for trace gas monitoring in ASCs; however, in 2013 Kwabia-Tchana et al. (2013) have demonstrated the ability to perform FT-farIR spectroscopy in a large cryogenically cooled Chernin cell (Kwabia-Tchana et al., 2013). This cell is coupled to the AILES beamline of the SOLEIL synchrotron (Brubach et al., 2010) and allows mid-IR and far-IR measurements with variable path lengths from 3 to more than $141 \mathrm{~m}$ thanks to exceptional properties of brightness and small divergence especially in the $\mathrm{THz}$ domain.

In this study, we present and characterize a multiple pass system developed for the CHamber for Atmospheric Reactivity and Metrology of the Environment (CHARME) (Fayad, 2019). Based on a Chernin type arrangement, the so named MULTICHARME has been dimensioned for the CHARME ASC and allows the monitoring of stable and reactive atmospheric species at trace levels over three decades of frequencies by probing long path rovibrational and rotational molecular absorbances respectively in the IR and in the $\mathrm{THz}$ domains. To the best of our knowledge, this is the first time that a $\mathrm{THz}$ spectrometer has been used for in situ measurements of atmospheric species in an ASC. The results obtained in this study highlight a new approach based on pure rotational spectroscopy for rapid and highly selective detection of stable and reactive atmospheric compounds in a simulated atmospheric environment. The first part of the article is dedicated to the description of CHARME, MULTICHARME and its coupling with IR and $\mathrm{THz}$ sources. The results are presented and discussed in the second part of the article with a special focus on the $\mathrm{THz}$ measurements which are unprecedented in the ASC community.

\section{Experimental setup and methodology}

\subsection{CHARME (CHamber for Atmospheric Reactivity and Metrology of the Environment)}

The CHARME is the new atmospheric simulation chamber designed in the LPCA (Laboratoire de Physico-Chimie de l'Atmosphère) laboratory in Dunkirk (France). CHARME is described in detail in Fayad (2019). Briefly, it consists of a $9.2 \mathrm{~m}^{3}$ evacuable cylinder (length $\approx 4 \mathrm{~m}$; internal diameter $\approx 1.7 \mathrm{~m}$ ) made of electropolished stainless steel $(304 \mathrm{~L})$. The inner surface of the reactor is mechanically polished in addition to an electrochemical treatment, which enhances the light reflectivity and also reduces the interaction of gases and particles with the walls. There are four stainless steel fans (diameter $50 \mathrm{~cm}$ ) located at the bottom of the chamber to assure a fast homogenization of the reactive mixtures and can be activated only at atmospheric pressure.

The rigid walls with a thickness varying from 4 to $40 \mathrm{~mm}$ permit the reactor to guarantee vacuum and nondeformation of the flanges. Consequently, CHARME is considered as vacuum compatible and it is capable of support- 
ing most of the mechanical constraints when it is under vacuum. The range of pressure under which it can operate is: $0.05 \mathrm{mbar}<P<1000 \mathrm{mbar}$. CHARME is pumped with a vacuum pump (Cobra NC0100-0300B) and is filled with purified and dried air at the required pressure using a generator (Parker Zander KA-MT 1-8). The pressure within the chamber is measured using 2 MKS BARATRON (626B13MDE (1000 mbar) and 626B01MDE (1 mbar)) and a pressure reader (MKS PR4000B) and the relative humidity and temperature are monitored by a combined probe (Vaisala HUMICAP, HMT330).

CHARME has 9 different circular access ports ranging from 45 to $20 \mathrm{~cm}$ in diameter (see Fig. S1 in the Supplement), which are used for various tasks: accommodate the MULTICHARME optical set-up for a Chernin cell described in this article; to provide physical access to the inside of the chamber for any cleaning and alignment operations; for in situ monitoring of gases and particles by incoherent broad band cavity enhanced absorption spectroscopy (IBBCEAS, Fiedler et al., 2003; Meng et al., 2020) to introduce gases and/or particles into the chamber.

\subsection{MULTICHARME (MULTI-pass cell specially designed for CHARME)}

\subsubsection{General design}

In order to ensure a sufficient optical throughput at $\mathrm{THz}$ frequencies the MULTICHARME Chernin cell configuration employed uses two rectangular field mirrors $(266 \times 310 \mathrm{~mm}$ and $222 \times 50 \mathrm{~mm}$ ), and three circular objective mirrors (diameter $130 \mathrm{~mm}$ ). As shown in Fig. 1b, we have opted for the modified version of the Chernin cell with the input and output windows on both sides of the field mirrors (Chernin, 2001). MULTICHARME has been designed in order to maximize the size of the mirrors to account for the large size of the beams and the strong divergences at longer wavelengths in the $\mathrm{THz}$ domain. We were nevertheless limited by the size of the flanges coupled to the DN 450 circular ports of the CHARME ASC. All mirrors have the same radius of curvature $(\mathrm{ROC}=5000 \mathrm{~mm}$ ) corresponding to the MULTICHARME base length. Fused silica substrates were used for the field mirrors, $\mathrm{K} 9$ for the objectives. To optimize the reflectivity from near-IR to $\mathrm{THz}$ domain, i.e. three frequency decades from 300 to $0.3 \mathrm{THz}$, a coating of $500 \mathrm{~nm}$ silver protected by $10 \mathrm{~nm}$ of $\mathrm{Al}_{2} \mathrm{O}_{3}$ was used. These relatively large mirrors were manufactured by the Anhui Institute of Optical and Fine Mechanics over a period of several months to build the substrates and to deposit the coatings. This institute has already successfully developed a Chernin cell for the detection of atmospheric radicals with Faraday rotation spectroscopy in the mid-IR (Fang et al., 2020).

The two optical mounts, equipped with the three objective mirrors and the two field mirrors, constitute the Chernin cell presented in Fig. 1. Using the DN 450 access ports (A1 and
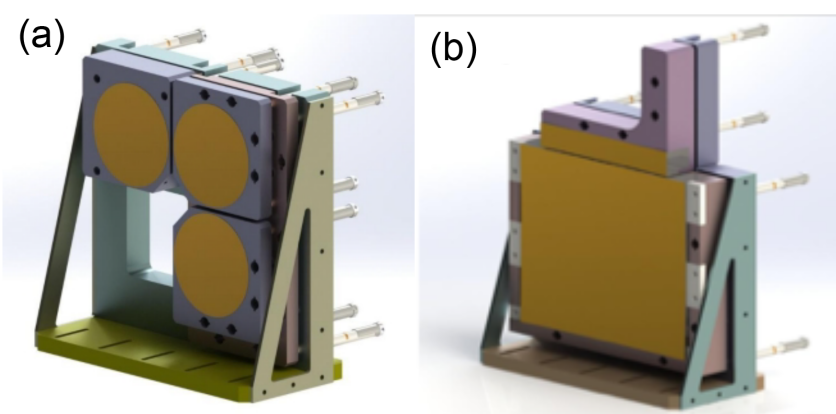

Figure 1. Schemes of the two mirror assemblies of MULTICHARME: the objective block (a) and the field block (b).

A2 in Fig. S1) and custom-made vacuum enclosures, they are located on opposite ends and placing the mirrors inside of the cylindrical chamber. Two aluminum optical mounts were constructed to hold the mirrors. The mass of the additional components added to CHARME was $160 \mathrm{~kg}$ for each of the two DN 450 ports located at opposite ends.

The total deformation of the Chernin cell and the corresponding mounting flanges were analyzed under static conditions. The forces that were considered were their own gravity and the atmospheric pressure on the outer surface of the flanges when the chamber was in a vacuum state. The maximum displacements have been estimated to be less than $30 \mu \mathrm{m}$. A picture of the five mirrors is given in Fig. S2. The characterization of their reflectivity in the IR and in the $\mathrm{THz}$ domains is described in Sect. 2.2.2 and 2.2.3, respectively. In order to accurately and easily control the optical alignment and the path length, both the field and objective mirrors are equipped with computer-controlled micrometric screws: MULTICHARME can be aligned with 18 compact linear motorized actuators TRA25PP from the MKS/Newport company (6 actuators are fixed on the field mount to adjust the 3 degrees of freedom of the 2 field mirrors; 12 actuators are on the objective mount: 9 to control the position of the 3 objective mirrors and 3 to adjust the relative orientation between field and objective blocks). The actuators are controlled by a home-made Arduino-based system located outside the cell (see Fig. S3). This system allows each actuator to be selected independently and to control their movement. The "5-mirror configuration" is easy to align, forms a matrix with an adjustable number of rows and even columns on the field mirrors and provides good vibration stability. Different spot patterns obtained with a He-Ne alignment laser are shown in Fig. S4 highlighting our ability to adjust matrix arrangement on the field mirror for different path lengths in MULTICHARME from 120 to $540 \mathrm{~m}$.

\subsubsection{Coupling with IR tunable diode laser}

The characterization in the near-IR has been performed using a continuous-wave external cavity diode laser (ECDL, Toptica DL pro) tunable from 1340 to $1450 \mathrm{~nm}$ with an output 
power of $80 \mathrm{~mW}$, a spectral width of $100 \mathrm{kHz}$ and a modehop free tuning range of $20 \mathrm{GHz}$. The ECDL source, the photodetector and the transfer optics were placed on an optical breadboard fixed to the field flange. The IR input and output were coupled to the CHARME ASC by two $76.2 \mathrm{~mm}$ diameter $\mathrm{ZnSe}$ windows with a $1^{\circ}$ wedge giving a theoretical transmission of about $70 \%$ at $1.4 \mu \mathrm{m}$.

The IR optical configuration is presented in Fig. 2b, an additional mirror was inserted into the beam path to coaxially inject a red MKS/Newport He-Ne laser $(5 \mathrm{~mW})$ with the IR beam axis in order to facilitate the alignment of the Chernin cell. This enables the IR path length in MULTICHARME to be evaluated by the observation of the matrix arrangement of the He-Ne spots on the field mirrors observed from a BK7 window placed on the objective transfer flange. All adjustments and path length changes can be made in situ, without venting CHARME, with the computer-controlled actuators. Once the laser was adjusted for the desired operating range, a wavelength calibration was performed (Burleigh WA-1500) with an accuracy better than $4 \times 10^{-3} \mathrm{~cm}^{-1}$. An InGaAs detector (Thorlabs PDA400) with a typical bandwidth of $10 \mathrm{MHz}$ was used for the detection. Spectra were obtained by applying a voltage ramp to the piezo actuator allowing an excursion of $0.17 \mathrm{~cm}^{-1}$ around the line center at a frequency of $1.3 \mathrm{~Hz}$. The received photodiode signal was averaged by a digital oscilloscope (DSO-X 2002A Agilent Technologies, maximum frequency $70 \mathrm{MHz}$ ). The signal was typically accumulated over 16 ramp cycles with a sampling of $12.5 \mathrm{kHz}$ (10 bits of vertical resolution).

To characterize the performance of MULTICHARME in the near-IR, we have examined the optical throughput in the modified Chernin multi-pass cell by measuring the output IR power for several different matrix arrangements (Glowacki et al., 2007a). It corresponds to 12 matrix configurations from 24 to 108 passes, for path lengths from $120 \mathrm{~m}$ ( 3 rows $\times 4$ columns) to $540 \mathrm{~m}$ ( 9 rows $\times 6$ columns), respectively. The output powers shown in Fig. 3 were measured with a PDA400 power-meter from Thorlabs with an accuracy of $1.2 \mu \mathrm{W}$. The variation of the output power with the number of reflections was modeled by a power law $P=A \times R_{\mathrm{eff}}^{n}$, where $A$ is a constant corresponding to the received power with no reflection, $R_{\text {eff }}$ is the effective mirror reflectivity at $1.4 \mu \mathrm{m}$ and $n$ is the number of reflections. An effective reflectivity of the mirrors at $1.4 \mu \mathrm{m}$ was adjusted to $95.98 \pm 0.06 \%$ (error given by the fit) with a weighted fit using the estimated error bars taking the accuracy of the IR photodetector into account. This value is relatively good considering the expected decrease of the IR reflectance at shorter wavelengths.

\subsubsection{Coupling with $\mathrm{THz}$ source}

Several compact and versatile solid-state sub- $\mathrm{THz}$ sources are currently used in our laboratory for trace gas monitoring using high resolution rotational signatures of atmospheric pollutants in realistic media, e.g. industrial combus- tion (Mouret et al., 2013) or gas emitted in food packaging (Hindle et al., 2018). In this study, a commercial Virginia Diode Inc amplified multiplication chain (AMC) driven by a microwave synthesizer (Rhodes \& Schwarz SMA 100B) was used (see Fig. 2c). Two Menlo systems TPX lenses of $50.8 \mathrm{~mm}$ diameter and $100 \mathrm{~mm}$ focal length were used to collimate the beam at the entrance of the chamber and refocus the output beam onto the detector. The propagation of the THz radiation in MULTICHARME was modeled as a Gaussian beam using a program developed by Lightmachinery inc. (Williams, 2019) showing that the use of $f=100 \mathrm{~mm}$ lens provides the best results taking into account the beam properties (waist and divergence), the dimension of MULTICHARME and the different losses (transmission through the window \& reflections on the field and objective mirrors). Two different AMC multiplication stages were used, the first (multiplication $\times 18$ ) to cover the 140 to $220 \mathrm{GHz}$ frequency region with an average power of $3 \mathrm{~mW}$ and the second (multiplication $\times 54$ ) to cover the 440 to $660 \mathrm{GHz}$ region with an output power of around $50 \mu \mathrm{W}$. To detect the MULTICHARME output THz signal, two VDI Schottky zero biased detectors (ZBD) WR5.1 and WR1.5 were chosen with typical responsivities of 1000 and $2400 \mathrm{~V} \mathrm{~W}^{-1}$, respectively for the first and the second stages. The typical noise equivalent power (NEP) of these Schottky diodes is estimated to be $10 \mathrm{pW} \sqrt{\mathrm{Hz}}^{-1}$. Both amplitude modulation (AM) and frequency modulation (FM) schemes were employed. The simultaneous use of AM and FM as a function of frequency proved useful to minimize the effects of the standing waves in the baseline, (see Sect. 3). A computer-controlled Ametek 7230 lock-in amplifier recovered the measured signal as a function of the frequency. High resistivity float zone silicon windows with a theoretical transmission of more than $50 \%$ were used for the entry and exit of MULTICHARME during the $\mathrm{THz}$ measurements. This material is opaque at the He$\mathrm{Ne}$ laser wavelength, so the THz beam alignment in MULTICHARME was performed by superimposing the $\mathrm{THz}$ beam onto the IR beam at the entrance of MULTICHARME and on the objective mirrors.

As done with the IR radiation, we have measured the $\mathrm{THz}$ output power for different path lengths. These measurements presented in Fig. 3b were performed around $190 \mathrm{GHz}$ corresponding to the maximum output power at the rank $\times 18$ of the AMC. With a lower input power and a more divergent beam, only 5 matrix configurations corresponding to path lengths from $120 \mathrm{~m}$ ( 24 passes) to $280 \mathrm{~m}$ (56 passes) were accessible at this frequency. If we consider just the detector NEP, $50 \mathrm{pW}$ should be detectable with a time constant of $1 \mathrm{~s}$, i.e. four orders of magnitude below the power level measured for a $280 \mathrm{~m}$ path length. Here the strong limitation to reach larger path lengths is the divergence of the $\mathrm{THz}$ radiation and the size of the THz waist on the field mirrors. Reaching a path length of $280 \mathrm{~m}$ with an amplified frequency multiplication chain which is a highly divergent source, is a significant im- 
(a)

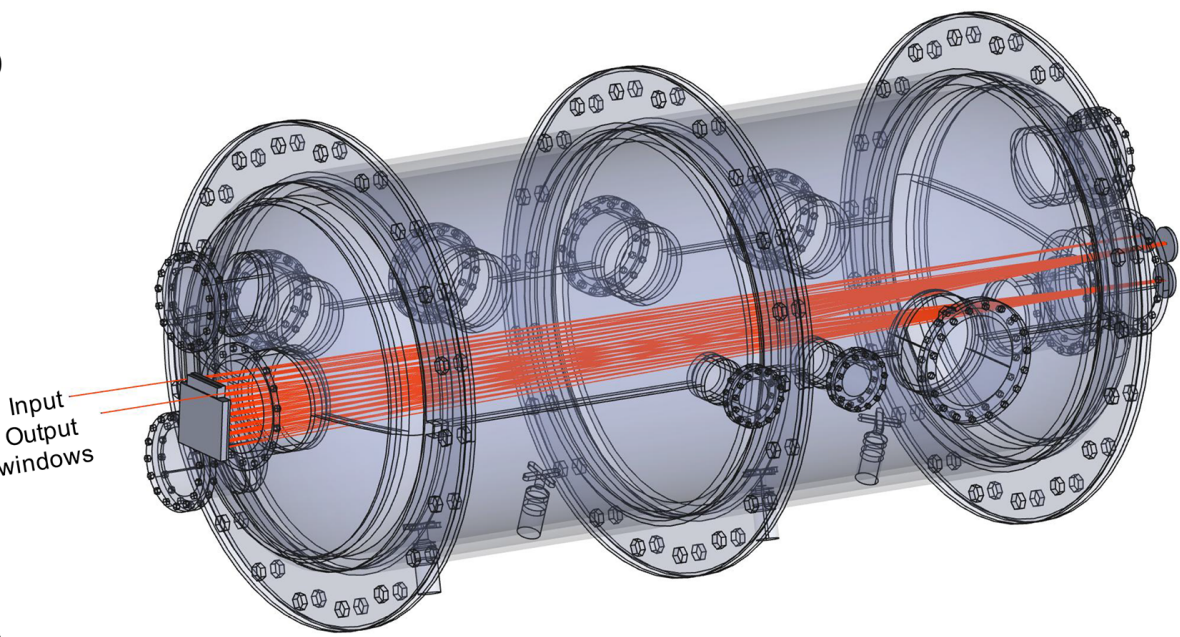

(b)

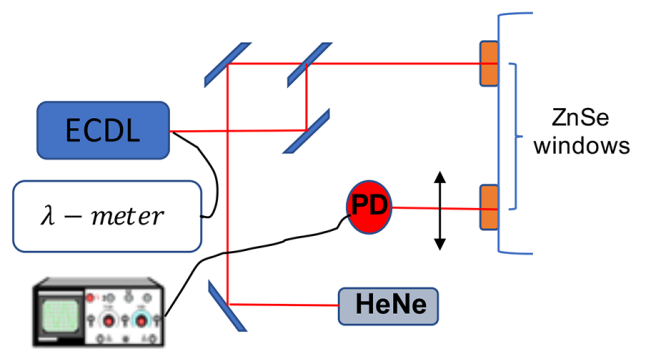

(c)

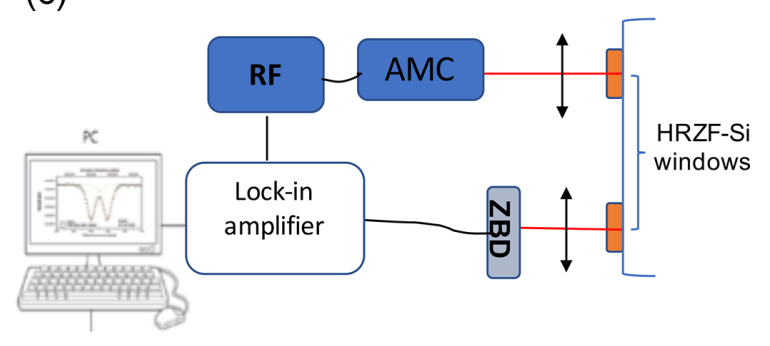

Figure 2. (a) 3D plot of MULTICHARME in CHARME performed with the FreeCad software and the Optics Workbench. (b) Near-IR coupling to MULTICHARME via ZnSe windows using an external cavity diode laser (ECDL), a standard photodiode (PD), a He-Ne laser for alignment and a wavelength meter ( $\lambda$-meter). (c) THz coupling to MULTICHARME via high resistivity float zone-silicon (HRFZ-Si) windows using an amplified multiplication chain (AMC) driven by a RF synthesizer and a zero-biased detector (ZBD) connected to a lock-in amplifier.

(a)

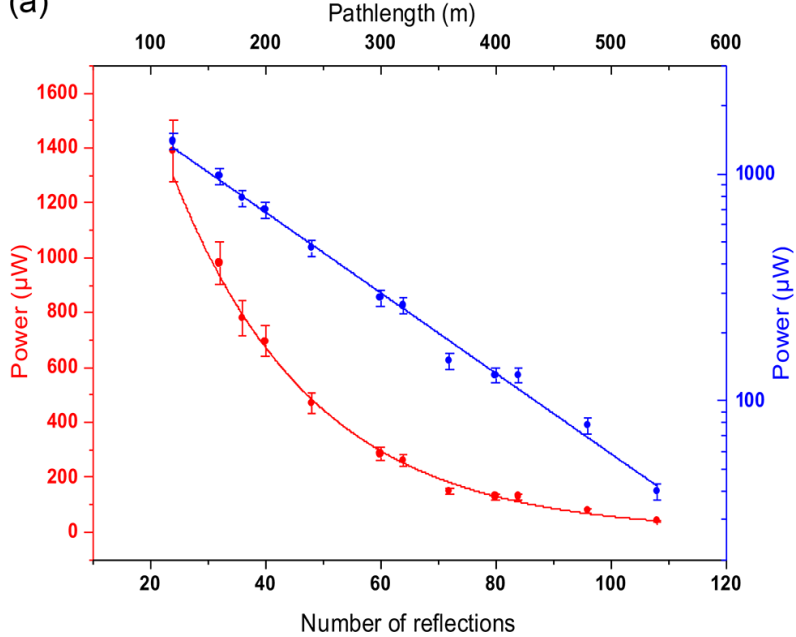

(b)

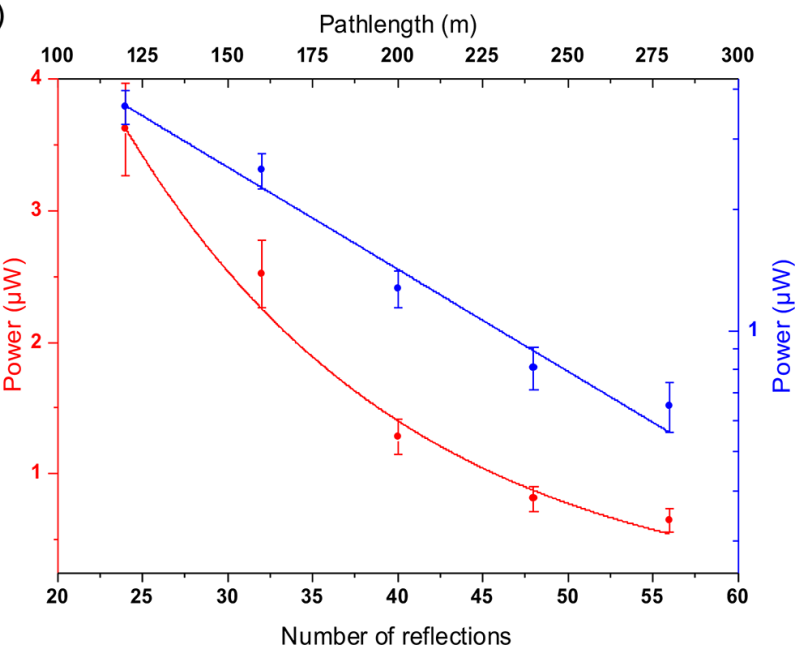

Figure 3. Attenuation of the IR (a) and the THz (b) output power (linear scale in red, log. scale in blue) vs. the number of the reflections in MULTICHARME. The effective IR and THz reflectivities are deduced from the fit of the measurements with the power law: $P=A \times R_{\text {eff }}^{n}$ (power law fit in red, linear fit in blue). The fits are performed with an instrumental weighting $\omega_{i}=1 / \sigma_{i}^{2}$ with $\sigma_{i}$ being the error bar sizes taking into account: the IR sensor uncertainty (5\%) and the accuracy of the controller sensor (3\%) for (a); the THz power fluctuations measured on the lock-in amplifier for (b). See Fig. S4 for spot matrix illustrations. 
provement compared to commonly used set-ups. Extending the path length further should be possible for higher frequencies or with more powerful $\mathrm{THz}$ sources. An overview of the best performance reached by rotational sub-mm-wave/ $\mathrm{THz}$ long-path absorption spectroscopy is provided (Cuisset et al., 2021): the maximum THz path length in a White-cell was obtained with a weakly divergent and bright synchrotron source but it never exceeded $200 \mathrm{~m}$ (Brubach et al., 2010); longer interaction path lengths are accessible only in Fabry-Perot resonators with intracavity spectroscopic techniques (Hindle et al., 2019). By fitting, with the power law, the THz output power, an effective $\mathrm{THz}$ reflectivity of $94.2 \pm 0.4 \%$ (error given by the fit) has been found for MULTICHARME. This value is only slightly lower than the near-IR value found in Fig. 2a. Therefore, MULTICHARME guarantees a reflectivity better than $94 \%$ on more than 3 decades of frequencies. With a unique modified Chernin type multi-pass cell, long path absorption spectroscopic measurements are now possible from the THz to the near-IR domain in an ASC such as CHARME.

\section{Results and discussion}

\subsection{Absorption linearities}

The first spectroscopic measurements were carried out to verify the linearity of the absorption over three decades of frequencies from mm-wave to near-IR domains. With the aim to characterize the performances of MULTICHARME, we have chosen nitrous oxide $\mathrm{N}_{2} \mathrm{O}$ as test molecule for three main reasons: (i) $\mathrm{N}_{2} \mathrm{O}$ is a powerful and very stable greenhouse gas which can be considered now as the dominant ozone-depleting substance emitted in the 21 st century in our atmosphere (Ravishankara et al., 2009). The monitoring of its chemical activity during transport from the troposphere to the stratosphere is crucial to control the ozone depletion; (ii) $\mathrm{N}_{2} \mathrm{O}$ is actually monitored in the troposphere and in the stratosphere by probing its rovibrational IR and rotational $\mathrm{THz}$ transitions with sounders such as the infrared atmospheric sounding interferometer (IASI) (Clerbaux et al., 2009) or THz atmospheric limb sounder (TALIS) (Wang et al., 2020) respectively; (iii) the molecular rotational and rovibrational line parameters (line frequencies, line widths, line intensities) of $\mathrm{N}_{2} \mathrm{O}$ were measured and calculated from the mm-wave to the near-IR domains and are listed in the international spectroscopic databases such as JPL (Pickett et al., 1998) or HITRAN (Gordon et al., 2022).

The absorption linearity was first checked in the nearIR by probing the $R(17)$ rovibrational transition of $\mathrm{N}_{2} \mathrm{O}$ in the highly excited $(3,2,0,1) \leftarrow(0,0,0,0)$ vibrational band. From the HITRAN database (Gordon et al., 2022), this line is predicted with a weak intensity $(S=7.1 \times$ $10^{-25} \mathrm{~cm} \mathrm{molecule}{ }^{-1}$ ) and is expected at $7149.45 \mathrm{~cm}^{-1}$, where the ECDL performs optimally. As shown in Fig. 4a, the near IR rovibrational absorbance has been obtained for 8 different paths in MULTICHARME covering interaction distances from 120 to $480 \mathrm{~m}$ at a pressure of $20 \mathrm{mbar}$. In order to avoid any saturation of the absorption signal, a calibrated mixture of $\chi=1000 \mathrm{ppmv}$ of $\mathrm{N}_{2} \mathrm{O}$ diluted in $\mathrm{N}_{2}$ was used. In order to deduce the absorbance given by $A(v)=\ln \frac{I_{0}(v)}{I(v)}$, baseline variations $I_{0}(v)$ were measured systematically with the signal variations $I(v)$. The wavenumber calibration was performed with the measurements of the WA-1500 wavelength-meter with an accuracy better than $4 \times 10^{-3} \mathrm{~cm}^{-1}$. The integrated absorbances, converted in $\mathrm{cm}^{-1}$ units, are determined by fitting the Doppler broadened near-IR lines with Gaussian profiles. They have been plotted in Fig. 4b according to the associated path lengths. A linear regression weighted with the error bars $(3 \sigma)$ deduced from the Gaussian fits yields an $R^{2}$ of 0.998 and a slope $s=$ $1.17(7) \times 10^{-5} \mathrm{~cm}^{-1} \mathrm{~m}^{-1}$. The linearity observed ensures the absence of saturation and guarantees that the IR photons introduced into MULTICHARME have traveled the same optical path before they reach the detector (Kwabia-Tchana et al., 2013). From the measured slope in Fig. $4 \mathrm{~b}$ and the averaged linewidth estimated to be $\Delta v=0.014 \mathrm{~cm}^{-1}$ (HWHM), we can deduce, according to the equation $\alpha_{0, \exp }=\sqrt[2]{\frac{\ln 2}{\pi}} \frac{s}{\Delta v}$ (Sigrist, 1994), an experimental value of the maximum absorption coefficient of the line $\alpha_{0, \exp }=3.92 \times 10^{-6} \mathrm{~cm}^{-1}$, around 50 times bigger than the expected value $\alpha_{0, \text { th }}=$ $7.26 \times 10^{-8} \mathrm{~cm}^{-1}$ given by the equation $\alpha_{0, \text { th }}=\frac{S \chi}{k_{\mathrm{B}} T \gamma_{\text {air }}}$ (Hindle et al., 2018), where the line intensity $S$ and the airbroadening coefficient $\gamma_{\text {air }}$ are the tabulated values in the HITRAN database. The variation between $\alpha_{0 \text {,exp }}$ deduced from our measurements and $\alpha_{0 \text {,th }}$ could be partially explained by significant uncertainties of the tabulated near-IR parameters $S$ and $\gamma_{\text {air }}$ from a very weak rovibrational line which was, to the best of our knowledge, never measured before this study.

The absorption linearity was also checked in the $\mathrm{THz}$ domain by probing the pure $R(22)$ rotational transition of $\mathrm{N}_{2} \mathrm{O}$ in its ground state expected at $577578.215 \mathrm{MHz}$ with a line intensity estimated to be $S=2.9 \times 10^{-22} \mathrm{~cm}^{-1}\left(\text { molecule } \mathrm{cm}^{-2}\right)^{-1}$ from the HITRAN database (Gordon et al., 2022), 400 times stronger than the previously probed near-IR rovibrational line and experimentally measured (Rohart et al., 2003). For the THz measurement, the mixing ratio in air was $400 \mathrm{ppmv}$ and the rotational lines were measured at a total pressure of 4 mbar. Unlike IR rovibrational bands, with only a few mbar of pressure, the collisional broadening is dominant compared to the Doppler broadening and a Lorentzian profile was assumed to fit these $\mathrm{THz}$ lines. The measured absorbances for five different path lengths from 120 to $280 \mathrm{~m}$ are presented in Fig. 5a. Compared to the IR lines, strong baseline oscillations due to standing $\mathrm{THz}$ waves affect the line profile especially for the longest $\mathrm{THz}$ paths. In Fig. 5b, we have determined the integrated absorbances by determining the area of the rotational lines shown in Fig. 5a. Compared to the 

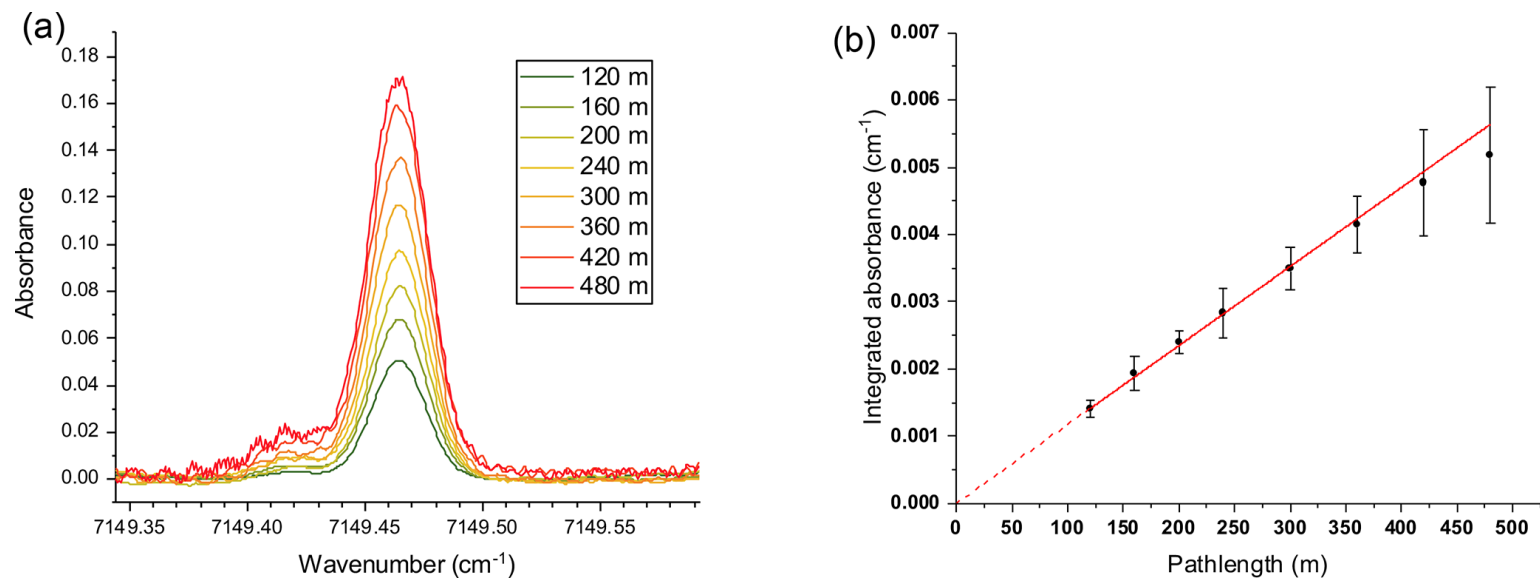

Figure 4. (a) Absorbance of the $R(17)$ rovibrational line of $\mathrm{N}_{2} \mathrm{O}$ in the $(3,2,0,1) \leftarrow(0,0,0,0)$ vibrational band measured with the ECDL IR source in the $7149.5 \mathrm{~cm}^{-1}$ region for 8 different path lengths in MULTICHARME $\left(\chi_{\mathrm{N}_{2}}=1000\right.$ ppmv and $\left.P=20 \mathrm{mbar}\right)$. The shoulder observed at low frequency is assigned to the ECDL source which is not perfectly monomodal in this region. (b) Linear fit of path length dependence of the integrated absorbances, instrumentally weighted on the error bars deduced from the Gaussian fits of the absorbances shown in (a).

IR results, larger uncertainties are deduced from the integration process due to the baseline variations. Nevertheless, a linear behavior is estimated with the different path lengths at least up to $240 \mathrm{~m}$ which already constitutes a record for a $\mathrm{THz}$ radiation in a multi-pass cell (Cuisset et al., 2021). With $s=5.1(4) \times 10^{-7} \mathrm{~cm}^{-1} \mathrm{~m}^{-1}$, the slope obtained with the four $\mathrm{THz}$ measurements from 120 to $240 \mathrm{~m}$ is smaller than the IR slope. The $\mathrm{THz}$ rotational linewidth is estimated to be $3.4 \times 10^{-4} \mathrm{~cm}^{-1}$ (HWHM), around 300 times smaller than the IR rovibrational linewidth highlighting the excellent selectivity of the $\mathrm{THz}$ spectroscopy compared to IR due to a weaker Doppler broadening. An associated value of $\alpha_{0, \exp }=$ $4.77 \times 10^{-6} \mathrm{~cm}^{-1}$ is deduced from the relation $\alpha_{0, \exp }=\frac{s}{\pi \Delta v}$ assuming pressure-broadened lines (Sigrist, 1994). Unlike the near-IR results, the measured maximum absorption $\alpha_{0 \text {,exp }}$ is in good agreement with the calculated value from the tabulated intensity $S$ and the air-broadening coefficient $\gamma_{\text {air }}$ yielding $\alpha_{0 \text {,th }}=1.23 \times 10^{-5} \mathrm{~cm}^{-1}$. There is no doubt that in this case, the rotational parameters of $\mathrm{N}_{2} \mathrm{O}$ are more reliable and here the slight differences between the two values are due to an absorbance averaged on the full line profile compared to an absorption $\alpha_{0 \text {,th }}$ calculated for the maximum of the rotational line.

\subsection{Specificity of the THz measurements}

Compared to IR rovibrational spectroscopy, rotational $\mathrm{THz}$ spectroscopy presents several advantages and disadvantages for the monitoring of atmospheric compounds in an ASC such as CHARME.

The main advantage deals with the selectivity of the technique at low pressure. Indeed, $\mathrm{THz}$ rotational linewidths have two main contributions: the temperature-dependent Doppler broadening and the pressure and temperature-dependent col- lisional broadening. The first contribution is the residual source of broadening at low pressure (below 1 mbar), the associated linewidth never exceeds a few $\mathrm{MHz}$ at $\mathrm{THz}$ frequencies giving rotational spectroscopy a much better selectivity than that obtained in IR gas phase rovibrational spectroscopy, especially for the light stable and reactive polar atmospheric compounds (De Lucia, 2010). Moreover we have demonstrated the ability of gas phase $\mathrm{THz}$ rotational spectroscopy to perform absolute quantification without any calibration step of targeted gaseous pollutants in complex chemical mixtures including both gases and particles (Bigourd et al., 2006, 2007; Mouret et al., 2013). Several measurements performed in realistic gas phase media contaminated with particles demonstrate that $\mathrm{THz}$ spectroscopy with submillimeter and mm-wavelengths is less sensitive to scattering than shorter wavelength IR and UV spectroscopy. Finally, due to the capabilities of the RF synthesizer driving the AMC $\mathrm{THz}$ source, the acquisition times (typically hundreds of $\mathrm{ms}$ ) are short and a time-resolved quantification providing kinetic parameters is also possible and simplified by using the $\mathrm{THz}$ electronic sources (Omar et al., 2015).

Despite these different advantages, some difficulties have to be underlined concerning $\mathrm{THz}$ monitoring of trace gases in ASC: (i) first, the output power level of the THz sources are significantly smaller than those of optical IR sources: as shown in Fig. 3, the THz measurements are performed at the $\mu \mathrm{W}$ level, at least two orders of magnitude lower than the power available in the near-IR measurements that inevitably affects the sensitivity of the detection scheme; (ii) the price to pay for maintaining an excellent selectivity is to carry out measurements at low pressures representative of the pressure levels of the upper atmosphere and a selective detection of rotational lines at tropospheric pressures is difficult to imag- 

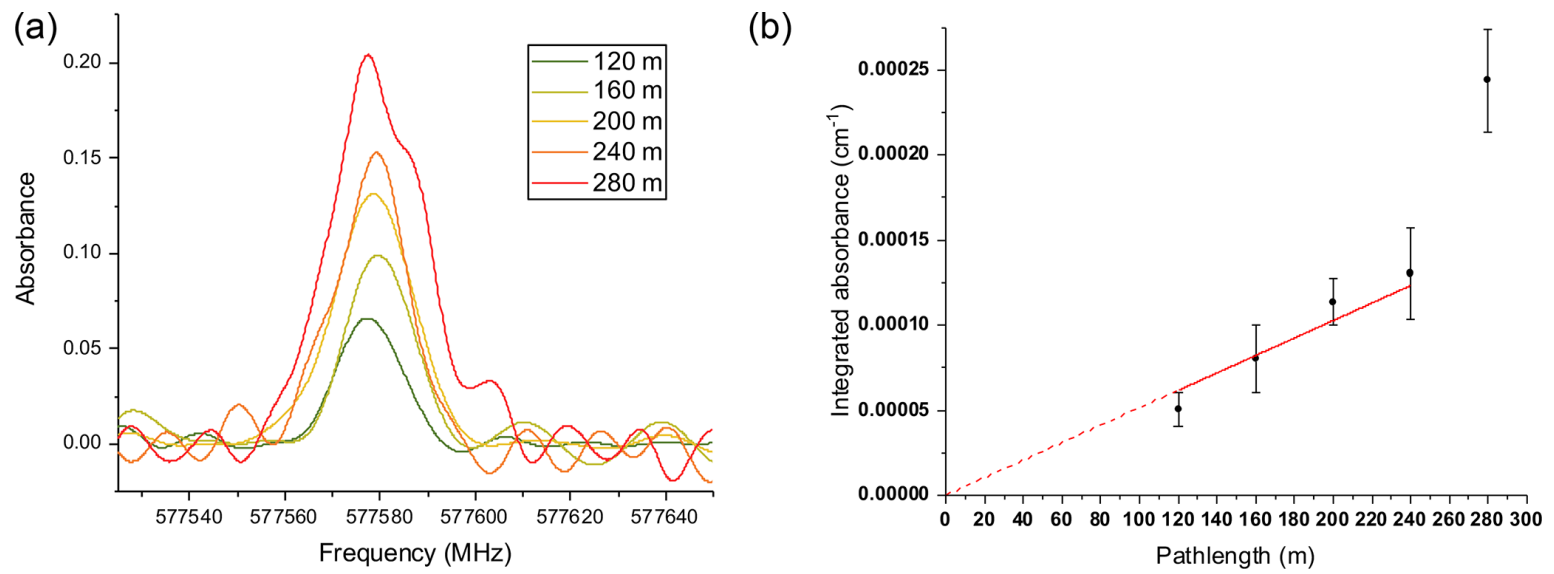

Figure 5. (a) Absorbance of the $R(22)$ rotational line of $\mathrm{N}_{2} \mathrm{O}$ in its ground state measured with the AMC THz source in the $577.58 \mathrm{GHz}$ region for 6 different path lengths in MULTICHARME ( $\chi_{\text {air }}=400 \mathrm{ppmv}, P=4 \mathrm{mbar}$ ). (b) Linear fit of the of path length dependence of the integrated absorbances instrumentally weighted on the error bars deduced from the Lorentzian fits of the absorbances shown in (a).

ine; (iii) finally, optical path lengths between 120 to $240 \mathrm{~m}$ produce standing waves with free spectral ranges (FSR) between $625 \mathrm{kHz}$ and $1.25 \mathrm{MHz}$ very close to the linewidths of the measured rotational absorptions. These standing waves strongly affect the baseline and the measured line profiles as observed in Fig. 4a. In Sect. 3.2, we demonstrate some possibilities offered by $\mathrm{THz}$ spectroscopic measurements in MULTICHARME taking into account the different advantages and disadvantages previously mentioned.

\subsubsection{Analysis of isotopic composition}

The $\mathrm{THz}$ rotational spectroscopy is a powerful technique for detection at low pressure due to its great selectivity allowing discrimination between: (i) polar compounds in complex chemical mixture (Bigourd et al., 2006, 2007; Mouret et al., 2013); (ii) isomers and stable conformers amongst VOCs (Roucou et al., 2018, 2020) and (iii) isotopomers of small polar atmospheric compounds in natural abundance (Hindle et al., 2019). For this last point, it has been demonstrated that $\mathrm{THz}$ rotational spectroscopy is able to determine relative isotopic abundances of small polar compounds with accuracies of a few \% (Lou et al., 2019). In order to highlight the selectivity of $\mathrm{THz}$ monitoring in MULTICHARME, we present in Fig. 6 some measurements of four different isotopomers of pure $\mathrm{N}_{2} \mathrm{O}$, in natural abundance. Table 1 summarizes abundances, line frequencies and intensities tabulated in spectroscopic databases (Pickett et al., 1998; Gordon et al., 2022). For the four isotopomers, the differences between the observed and the JPL frequencies never exceed $500 \mathrm{kHz}$. In Fig. 6a, for each path length the absorption of the $R$ (23) rotational transition of the most abundant ${ }^{14} \mathrm{~N}^{14} \mathrm{~N}^{16} \mathrm{O}$ isotopomer is saturated. Nevertheless, the equivalent transition for the ${ }^{14} \mathrm{~N}^{15} \mathrm{~N}^{16} \mathrm{O}$ expected to be only $43 \mathrm{MHz}\left(1.4 \times 10^{-3} \mathrm{~cm}^{-1}\right)$ lower in frequency with an intensity around 260 times weaker is clearly observed and re- solved. The other monosubstituted isotopomers ${ }^{15} \mathrm{~N}^{14} \mathrm{~N}^{16} \mathrm{O}$ and ${ }^{14} \mathrm{~N}^{14} \mathrm{~N}^{18} \mathrm{O}$ are also observed with the shortest path length $L=120 \mathrm{~m}$ at a pressure close to $1 \mathrm{mbar}$ (Fig. 6b). An isotopic ratio $\left[{ }^{15} \mathrm{~N}^{14} \mathrm{~N}^{16} \mathrm{O}\right] /\left[{ }^{14} \mathrm{~N}^{14} \mathrm{~N}^{18} \mathrm{O}\right]$ of 1.87 is deduced from the intensities of the two absorption lines plotted in Fig. $6 \mathrm{~b}$. This value is sufficiently close to the expected value of 1.83 deduced from the natural abundances in Table 1 to suggest the possibility to use $\mathrm{THz}$ spectroscopy with MULTICHARME for the analysis of the isotopic composition of atmospheric trace gases and to detect anomalous isotopic signatures, a powerful approach to identify sources and sinks of pollutants and/or greenhouse gases (Röckmann et al., 2001).

Finally the discrimination of the $\mathrm{N}_{2} \mathrm{O}$ isotopomer rotational lines (especially the lines of ${ }^{14} \mathrm{~N}^{15} \mathrm{~N}^{16} \mathrm{O}$ and ${ }^{14} \mathrm{~N}^{14} \mathrm{~N}^{16} \mathrm{O}$ on Fig. 6a) highlights the exceptional selectivity of the $\mathrm{THz}$ rotational spectroscopy. Indeed, when the measurements are performed at low pressure (typically stratospheric pressures) the line widths converge to the Doppler limit. For molecules such as $\mathrm{N}_{2} \mathrm{O}$, the Doppler line widths, proportional to the line frequencies, typically vary from hundreds of $\mathrm{kHz}$ in the $\mathrm{THz}$ domain to hundreds of $\mathrm{MHz}$ in the IR and to several GHz in the UV visible domains. There is no doubt that $\mathrm{THz}$ high-resolution monitoring exhibits a significantly better selectivity compared to the IR/UV. In complex chemical mixtures studied in ASC, the THz method allows individual molecular signatures to be observed and resolved even for compounds with close molecular structures (isomers, conformers, isotopomers etc.). Moreover, the highresolution $\mathrm{THz}$ method strongly limits the problem of interference substances in the gas monitoring. With photon detection in the IR/UV spectral domain, it is generally not possible to resolve individual rovibrational or rovibronic transitions with the typical instrumental resolutions (e.g resolutions of FTIR spectrometers coupled to ASC are limited to few $\mathrm{GHz}$ ) and some corrections due to interferences with other species 
(a)

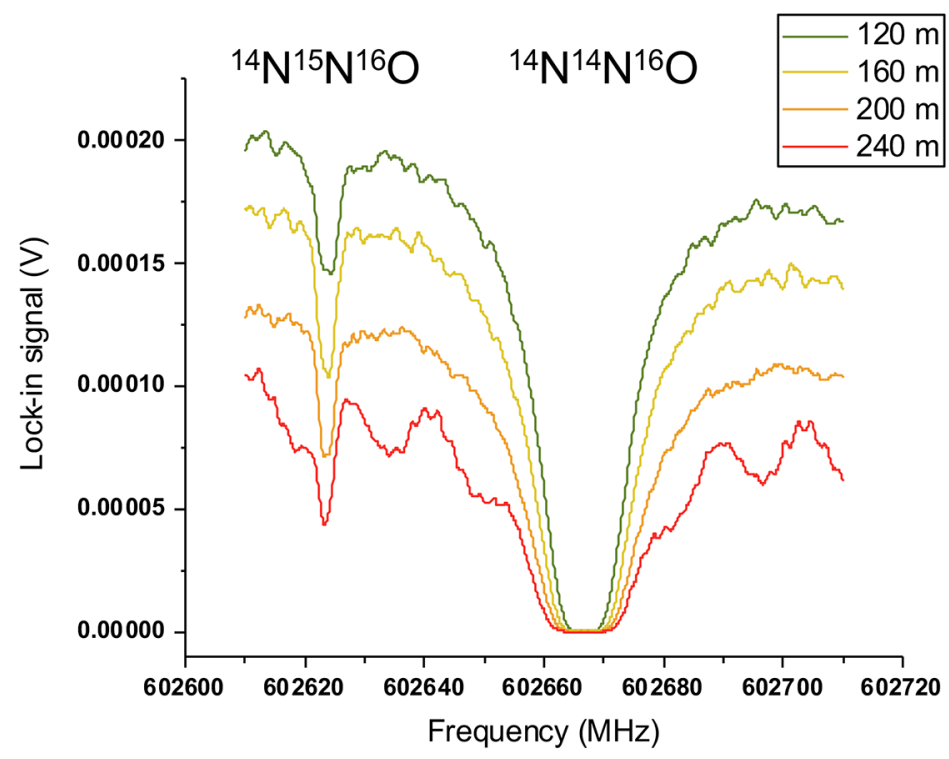

(b)
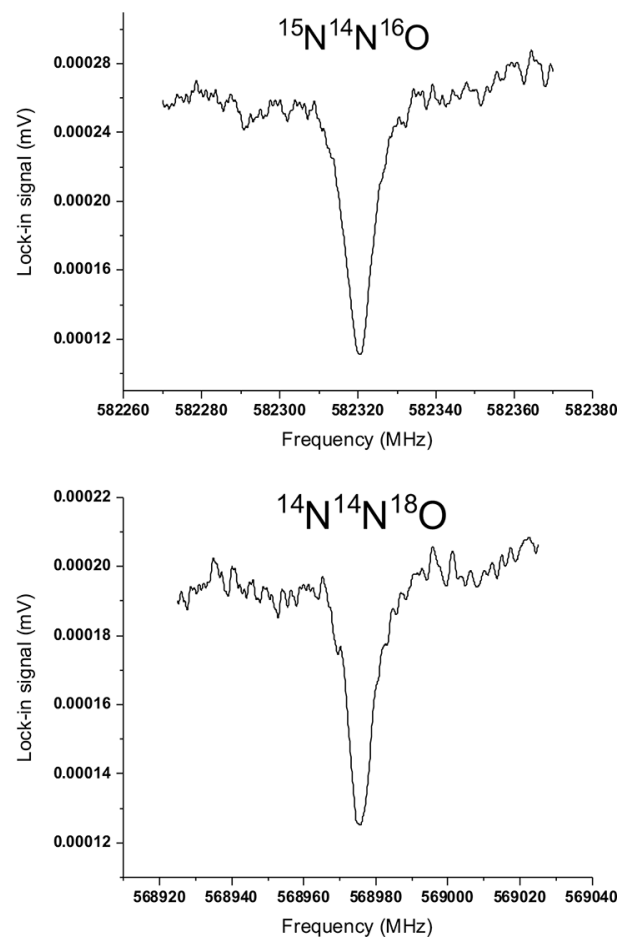

Figure 6. $\mathrm{THz}$ absorptions of four different $\mathrm{N}_{2} \mathrm{O}$ isotopomers in MULTICHARME measured without baseline treatment. (a) $R(23)$ rotational transition measured at $P=0.36$ mbar for the most abundant ${ }^{14} \mathrm{~N}^{14} \mathrm{~N}^{16} \mathrm{O}$ and the less abundant ${ }^{14} \mathrm{~N}^{15} \mathrm{~N}^{16} \mathrm{O}$ isotopomers; measurements are performed for four optical path lengths between 120 to $240 \mathrm{~m}$ (in each case the ${ }^{14} \mathrm{~N}^{14} \mathrm{~N}^{16} \mathrm{O}$ absorption is saturated). (b) Measurements at $P \sim 1$ mbar and $L=120 \mathrm{~m}$, lower in frequency, of the same rotational transition for the ${ }^{15} \mathrm{~N}^{14} \mathrm{~N}^{16} \mathrm{O}$ and ${ }^{14} \mathrm{~N}^{14} \mathrm{~N}^{18} \mathrm{O}$ isotopomers.

Table 1. Natural abundances of the four most abundant isotopomers of $\mathrm{N}_{2} \mathrm{O}$ (Gordon et al., 2022). Tabulated line intensity and frequency of the $R(23)$ rotational transition from the JPL (Pickett et al., 1998) and the HITRAN (Gordon et al., 2022) databases, respectively. Differences between tabulated and measured frequencies in Fig. 6.

\begin{tabular}{|c|c|c|c|c|}
\hline Isotopomer & $\begin{array}{r}\text { Natural abundance } \\
(\%)\end{array}$ & $\begin{array}{r}\text { Line intensity } \\
\left(\mathrm{cm}^{-1}\left(\text { molec.cm }{ }^{-2}\right)^{-1}\right)\end{array}$ & $\begin{array}{r}\text { Line frequency } \\
(\mathrm{MHz})\end{array}$ & $\begin{array}{r}\text { obs-calc } \\
(\mathrm{MHz})\end{array}$ \\
\hline${ }^{14} \mathrm{~N}^{14} \mathrm{~N}^{16} \mathrm{O}$ & 99.0333 & $2.9 \times 10^{-22}$ & 602666.49 & 0.41 \\
\hline${ }^{14} \mathrm{~N}^{15} \mathrm{~N}^{16} \mathrm{O}$ & 0.3641 & $1.11 \times 10^{-24}$ & 602623.41 & 0.06 \\
\hline${ }^{15} \mathrm{~N}^{14} \mathrm{~N}^{16} \mathrm{O}$ & 0.3641 & $1.05 \times 10^{-24}$ & 582320.00 & 0.45 \\
\hline${ }^{14} \mathrm{~N}^{14} \mathrm{~N}^{18} \mathrm{O}$ & 0.1986 & $5.22 \times 10^{-25}$ & 568975.30 & 0.25 \\
\hline
\end{tabular}

have to be taken into account in the trace gas quantification (Harris et al., 2020).

\subsubsection{Absolute quantification of stable and reactive atmospheric traces}

A priori all the polar compounds may be detected and quantified from their rotational signatures. In practice, for $\mathrm{THz}$ atmospheric monitoring at trace levels, we must opt for the lighter and the more strongly polar compounds with intense and resolved rotational transitions generally listed in the international databases. For these molecules, rotational line frequencies, line widths and line intensities are known with a good degree of accuracy allowing, if the line profile is pre- served during the measurement, an absolute quantification without any standard of calibration.

In the present article, we demonstrate this statement in Fig. 7a by fitting the absorbance of the $R(22)$ rotational line of $\mathrm{N}_{2} \mathrm{O}$ diluted in $\mathrm{N}_{2}$ at 1000 ppmv with a Voigt profile . Prior to the fit, two baseline treatments have be done in order to reduce the oscillations due to standing waves occurring in MULTICHARME: first of all, due to the capacities of the RF synthesizer, we have applied simultaneously to the amplitude modulation (AM) a rapid frequency modulation (FM) with a depth exceeding the FSR of the interaction length allowing a partial minimization of the effects of the standing waves. Next, during the posttreatment of the recorded signal leading to the absorbances shown in Fig. 7, an FFT filter was used 
to further reduce the rapid oscillations of the baseline. This treatment is described in Fig. S5. We have been careful that the postprocessing does not affect the line shape and hence the error of the resulting number density. The number density of absorbing $\mathrm{N}_{2} \mathrm{O}$ molecules in molec. $\mathrm{cm}^{-3}$ is directly deduced from the relation: $N=\frac{\int A(v) \mathrm{d} v}{S \times L}$ with the numerator $\int A(v) \mathrm{d} v$ corresponding to the integral, in $\mathrm{cm}^{-1}$ units, of the fitted absorbance by a Voigt profile and for the denominator the product of the line intensity $S$ in cm molecule ${ }^{-1}$ tabulated in HITRAN (Gordon et al., 2022) with the path length $L$ in cm. Finally the mixing ratio $\chi$ is deduced by: $\chi=\frac{N}{P} k_{\mathrm{B}} T$ with $P$ and $T$, the pressure and the temperature in CHARME during the measurement.

In Fig. 7a, an integrated absorbance of $2.4 \pm 0.3 \mathrm{MHz}$ was fitted giving a $\mathrm{N}_{2} \mathrm{O}$ number density of $N=(1.4 \pm 0.2) \times 10^{13}$ molec. $\mathrm{cm}^{-3}$ and a mixing ratio $1140 \pm 160$ ppmv. Taking into account the uncertainty of the fit, mainly due to the remaining baseline oscillations, the density number estimated by the absolute quantification procedure is in agreement with the value of the standard gas used. Based on the previous method, another example is given in Fig. $7 \mathrm{~b}$ with the quantification of unknown quantity of ozone in CHARME. Ozone is a key compound in atmospheric chemistry, both in the troposphere and stratosphere (Finlayson-Pitts and Pitts Jr., 1999) and a real time in situ monitoring of reactive ozone is very interesting for numerous ozonolysis reactions occurring in our atmosphere especially with VOCs. In our study, ozone was produced at atmospheric pressure by a generator (Air Tree Ozone Technology C-L010-DTI), which converts $\mathrm{O}_{2}$ into $\mathrm{O}_{3}$ from zero air exposed to a high voltage corona discharge. Based on the calibration of the ozone generator, performed with a photometric $\mathrm{O}_{3}$ analyzer, and the injection time $(90 \mathrm{~min})$, the ozone volume ratio introduced in CHARME was estimated to be around $500 \mathrm{ppmv}$. Then the ASC was pumped down (in $45 \mathrm{~min}$ ) to $1.5 \mathrm{mbar}$ and the $\mathrm{THz}$ spectrometer was used to detect and quantify $\mathrm{O}_{3}$ traces from individual rotational transitions. The $\mathrm{O}_{3}$ wall losses occurring during the ozone introduction as well as during the pumping procedure contribute to reduce the ozone mixing ratio to an unknown lower value which is measured by $\mathrm{THz}$ spectroscopy. Ozone is an asymmetric top with a large number of rotational transitions in the $\mathrm{THz}$ domain and its rotational frequencies and intensities have been determined with accuracy in the THz domain (Colmont et al., 2005; Birk et al., 1994). The $25_{1,25} \leftarrow 24_{0,24}$ transition centered around $610 \mathrm{GHz}$ with a tabulated intensity of $S=4.035 \times 10^{-22} \mathrm{~cm} \mathrm{molecule}^{-1}$, the most intense on the source's band emission, was chosen for this reason. A mixing ratio of $258 \pm 22 \mathrm{ppmv}$ was deduced from the fit of a Voigt profile to the line presented in Fig. 7b. This value is around two times lower than the initial concentration injected in the ASC at atmospheric pressure. This difference is due to the losses on the chamber walls during the ozone injection and the pumping times from atmospheric pressure to $1.5 \mathrm{mbar}$ (135 min). In Sect. 3.2.3, we show how to characterize at low pressure the kinetics of the $\mathrm{O}_{3}$ losses on the CHARME walls by $\mathrm{THz}$ monitoring.

In order to determine the limit of detection (LOD), we have considered the baseline oscillations as our detection noise and the LOD as the concentration obtained with a signal to noise $(S / N)$ ratio equal to 1 . Both for $\mathrm{N}_{2} \mathrm{O}$ and $\mathrm{O}_{3}$, the $S / N$ of Fig. 7 are estimated to 15 by taking the maximum amplitude of the rotational line as signal and the maximum of the amplitude of the residual away from the line as noise. Therefore, an LOD of around 75 and 15 ppmv may be estimated respectively for $\mathrm{N}_{2} \mathrm{O}$ and $\mathrm{O}_{3}$. These LOD are slightly lower than the mixing ratio errors obtained with the uncertainties on the fitted area. For $\mathrm{N}_{2} \mathrm{O}$, the LOD obtained by $\mathrm{THz}$ spectroscopy in this study are more than three orders of magnitude larger than the LOD on the strongest mid-IR rovibrational bands by tunable diode laser spectroscopy (TDLAS) even with measurements at low pressure (Hoor et al., 1999). With the THz method, for instance the LOD is limited to 15 ppmv. Using incoherent broad band cavity-enhanced absorption spectroscopy in the visible domain, an LOD of $120 \mathrm{ppbv}$ was obtained in the Dunkirk ASC at atmospheric pressure (Wu et al., 2014). In order to improve the sensitivity of the $\mathrm{THz}$ method, we have to correctly model the baseline and to remove its variations due to multiple interfering stationary waves in MULTICHARME. Work is under progress to this goal.

\subsubsection{THz monitoring of the ozone decay in CHARME}

In Fig. 8, we demonstrate the ability of the THz source coupled to MULTICHARME to monitor the ozone reactivity at low pressure in CHARME. To achieve the same $\mathrm{O}_{3} 25_{1,25} \leftarrow$ $24_{0,24}$ rotational transition centered at $610365.35 \mathrm{MHz}$ was targeted and measured during $12 \mathrm{~h}$, over a frequency range of $60 \mathrm{MHz}$, every $3 \mathrm{~min}$. Then 240 absorbance spectra were obtained and their time evolution as a $3 \mathrm{D}$ plot is shown in Fig. 8a. For each spectrum, we have repeated the baseline treatment and the line profile fit described in Fig. $7 \mathrm{~b}$. Then the data treatment to obtain the 240 absorbances of Fig. $8 \mathrm{a}$ and the 240 mixing ratios of Fig. $8 \mathrm{~b}$ has been batch processed with the Origin Software. As shown in Fig. 8b, the ozone concentration decreases exponentially from 230 to $15 \mathrm{ppmv}$ in $12 \mathrm{~h}$. We have considered the first-order kinetics of the ozone decay due mainly to the ozone losses on the chamber walls. The concentration decrease was fitted using the exponential law $\left[\mathrm{O}_{3}\right]_{t}=\left[\mathrm{O}_{3}\right]_{0} e^{-t / \tau_{\mathrm{O}_{3}}}$. A lifetime $\tau_{\mathrm{O}_{3}}$ of $3.4 \pm 0.1 \mathrm{~h}$ was deduced from a fit weighted on the instrumental errors corresponding here to LODs estimated with the same method as explained in the previous subsection with the Fig. 7b. In the present case, we can see that for ozone concentrations lower than $50 \mathrm{ppmv}$, the lower error bars point to zero or negative values indicating that the LOD is reached at this level of concentration. 
(a)

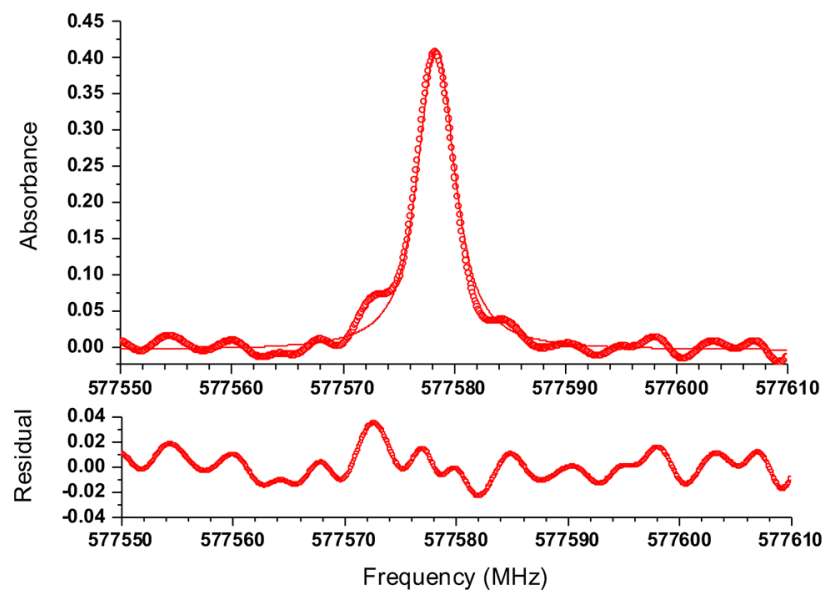

(b)

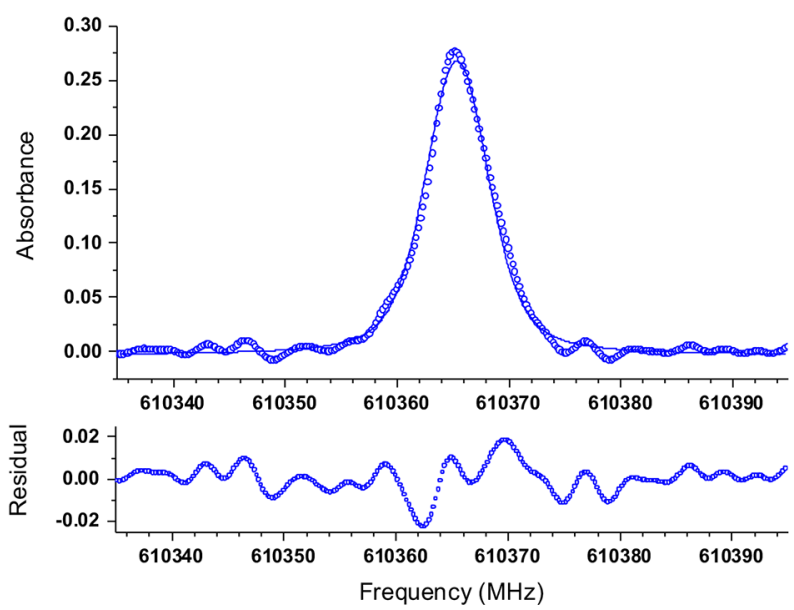

Figure 7. THz trace gas quantification of stable $\mathrm{N}_{2} \mathrm{O}$ and reactive $\mathrm{O}_{3}$ in MULTICHARME. (a) Red circles: $R(22)$ transition of 1000 ppmv $\mathrm{N}_{2} \mathrm{O}$ diluted in $\mathrm{N}_{2}$ measured at $P=0.5 \mathrm{mbar}$ (AM: $f_{\bmod }=4.5 \mathrm{kHz}+\mathrm{FM}: f_{\mathrm{mod}}=50 \mathrm{kHz}, \omega_{\mathrm{depth}}=1.44 \mathrm{MHz}$ ); red solid line: fit with a Voigt profile $\left(\int A(v) \mathrm{d} v=2.4(3) \mathrm{MHz} ; v=577578,36 \mathrm{MHz}\right.$ ). (b) Blue circles: $25_{1,25} \leftarrow 24_{0,24}$ transition of an unknown quantity of $\mathrm{O}_{3}$ diluted in air produced by an ozone generator measured at $P=1.5 \mathrm{mbar}$ (AM: $f_{\bmod }=4.5 \mathrm{kHz}+\mathrm{FM}: f_{\bmod }=50 \mathrm{kHz}, \omega_{\mathrm{depth}}=1.08 \mathrm{MHz}$ ); blue solid line: fit with a Voigt profile $\left(\int A(v) \mathrm{d} v=2.3(2) \mathrm{MHz} ; v=610365,35 \mathrm{MHz}\right)$. The residuals between the Voigt fit and the experimental points are given for both lines.

(a)

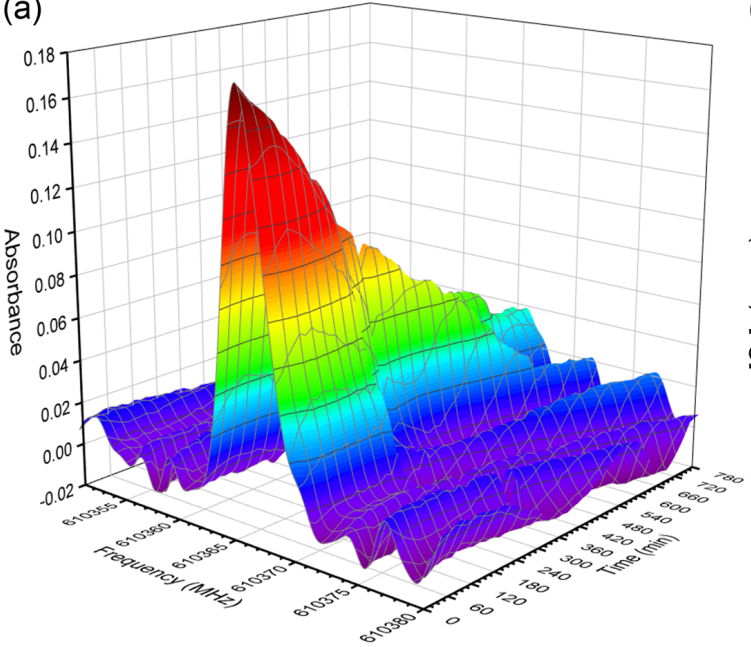

(b)

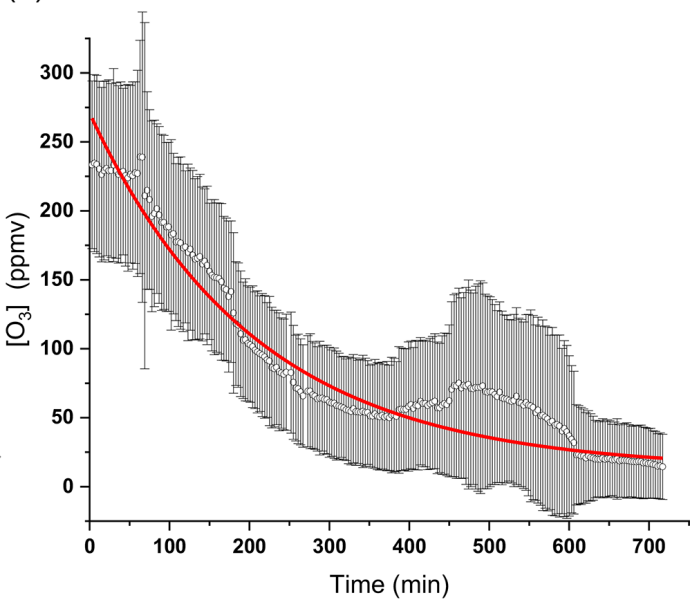

Figure 8. THz monitoring of the ozone decay in CHARME measured for $12 \mathrm{~h}$ at $P=1.1 \mathrm{mbar}$. (a) 3D plot of absorbance spectra measured every 3 min of the $\mathrm{O}_{3} 25_{1,25} \leftarrow 24_{0,24}$ rotational transition as a function of frequency (in $\mathrm{MHz}$ ) and time (in min). (b) First-order exponential fit of the ozone concentration decay in CHARME deduced by batch processing of the absorbances shown in (a). A lifetime $\tau_{\mathrm{O}_{3}}$ of $3.4 \pm 0.1 \mathrm{~h}$ is deduced from a weighted fit using the LODs as instrumental errors.

The losses of ozone in CHARME have already been investigated at atmospheric pressure with a UV-photometric analyzer (Thermo Scientific 49i; $\lambda=254 \mathrm{~nm}$ ). Using several initial concentrations, from 0.7 to $4.8 \mathrm{ppmv}$, the $\mathrm{O}_{3}$ lifetimes $\tau_{\mathrm{O}_{3}}$ were deduced from the first-order kinetics $\mathrm{O}_{3}$ wall loss reactions and varied from 6.2 to $13.8 \mathrm{~h}$ (Fayad, 2019), depending on the cleanliness of the chamber walls, which can change for different initial concentrations of ozone. Compared to the previous measurements performed in CHARME with a UV photometry analyzer, a shorter lifetime was determined by our low pressure $\mathrm{THz}$ measurements. Itoh et al. $(2004,2011)$ have developed and experimentally verified a physical model enabling understanding of the pressure and the wall material dependencies of the ozone-to-wall loss rate in a cylindrical tube (Itoh et al., 2004, 2011). They showed that the variation of the ozone lifetime with the pressure due to wall losses can 
be reproduced by the Eq. (1):

$\frac{1}{\tau_{\mathrm{O}_{3}}} \sim \frac{D_{\mathrm{e}}}{P} f(\alpha, l, \beta)+k N P$,

where $P$ is the pressure, $N$ is the molecular density, $f(\alpha, l, \beta)$ is a function depending on geometrical and surface properties of the chamber ( $a$ and $l$ are the radius and the length of the cylinder, respectively and $\beta$ is a surface parameter), $D_{\mathrm{e}}$ is an equivalent diffusion coefficient giving the magnitude of the surface loss rate of ozone according to the material and $k$ is a loss rate coefficient due to collisions with oxygen (Itoh et al., 2011). The pressure measurement conditions in $\mathrm{THz}$ rotational high-resolution spectroscopy are typical for chamber cleaning activities. Under these conditions it is known that the $\mathrm{O}_{3}$ loss in the chamber is dominated by wall reactions and not by reactions with $\mathrm{O}_{2}$. It corresponds to the first term of Eq. (1) and, therefore, as it is shown by our results, a decrease of the lifetime at low pressure was expected due to the reinforcement of the losses by the ozone diffusion on the chamber wall. That is why these conditions are chosen to get rid of impurities, such as VOCs, on the chamber wall.

\section{Conclusions}

We have developed for the Dunkirk ASC CHARME a Chernin-type multi-pass cell allowing performance of spectroscopic measurements over approximately three decades of frequencies from the submillimeter-wave spectral domain to the near-IR. In this study, the performances of MULTICHARME have been characterized in the near-IR region using a diode laser source oscillating around $1.4 \mu \mathrm{m}$ and in the $\mathrm{THz}$ region around $600 \mathrm{GHz}$ with a compact and versatile AMC. Benefiting from a base dimension of $5 \mathrm{~m}$, MULTICHARME enables very long optical paths to be reached for absorption spectroscopy from 120 to $280 \mathrm{~m}$ in the THz domain and to $480 \mathrm{~m}$. in the IR. The output powers have been measured for the different path lengths and an effective mirror reflectivity better than $94 \%$ has been measured both in the $\mathrm{THz}$ and in the near-IR. By targeting rovibrational and rotational transitions of the $\mathrm{N}_{2} \mathrm{O}$ greenhouse gas, the linearity of the integrated absorbances has been checked and experimental values of the maximum absorption coefficient were deduced and compared to the expected values deduced from the tabulated spectroscopic parameters. The THz monitoring of atmospheric compounds presents some specificities in comparison with other spectroscopic techniques: as an example, the measurements of the rotational lines of the most abundant isotopomers of $\mathrm{N}_{2} \mathrm{O}$ highlight the exceptional selectivity of the technique, which should be able to detect anomalous isotopic fractionation. Moreover the rotational absorbance allows an absolute quantification of the absorbing compound without a standard calibration. The demonstration was performed on stable $\mathrm{N}_{2} \mathrm{O}$ and reactive $\mathrm{O}_{3}$ greenhouse gases. According to the measured $S / N$ ratio, the LOD are limited to 75 ppmv for $\mathrm{N}_{2} \mathrm{O}$ and 15 ppmv for $\mathrm{O}_{3}$ due to the baseline oscillations involving numerous standing waves occurring in MULTICHARME. Work is in progress to characterize how these standing waves affect the detected $\mathrm{THz}$ signal in the modified Chernin-cell and to study the possibility to correctly model the $\mathrm{THz}$ baseline oscillations. This step is required to improve the sensitivity of the method in order to reach subppmv LOD for most small polar atmospheric molecules showing intense rotational transitions at $\mathrm{THz}$ frequencies. We have also to think about the possibility in the future to couple a $\mathrm{THz}$ cavity ring-down spectrometer to CHARME (Hindle et al., 2019), in this way we hope to be competitive with IR and UV-visible techniques in terms of LOD. Finally, THz monitoring has been used to quantify the decay of ozone at low pressure in CHARME. The ozone lifetime of $3.4 \pm 0.1 \mathrm{~h}$ deduced at low pressure in the chamber by $\mathrm{THz}$ spectroscopy is shorter than those obtained in previous measurements at atmospheric pressure using a UV photometry analyzer. At low pressure the ozone losses by diffusion on the ASC are accentuated.

This work demonstrates that $\mathrm{THz}$ monitoring is able to quantify gaseous compounds in an ASC such as CHARME and will allow the determination of kinetic rate coefficients as well as reactional pathways for targeted atmospheric processes. In the future, we plan to couple a Fourier transform interferometer to MULTICHARME allowing study of the tropospheric reactivity of VOCs at medium resolution $\left(0.5 \mathrm{~cm}^{-1}\right)$ using vibrational spectroscopy on a broadband spectral range from the far to the near-IR domains (20$8000 \mathrm{~cm}^{-1}$ ). Moreover, THz high-resolution rotational spectroscopy will be used in CHARME for the study of the stratospheric processes at low pressures (few mbars) and low temperatures $\left(T<-20^{\circ} \mathrm{C}\right.$ obtained by cryocooling). In particular the chemistry of stable and unstable halogenated species involved in the catalytic destruction of stratospheric ozone are good candidates for these future experiments as the rotational transitions of the stable $\mathrm{HX}, \mathrm{CH}_{3} X$ and unstable $\mathrm{O} X$ $(X=\mathrm{F}, \mathrm{Cl}, \mathrm{Br}, \mathrm{I})$ compounds lie in the $\mathrm{THz}$ domain and are sufficiently intense for monitoring at trace levels (Pickett et al., 1998).

Data availability. Data are available upon request to the corresponding author.

Supplement. The supplement related to this article is available online at: https://doi.org/10.5194/amt-15-1201-2022-supplement.

Author contributions. AC was involved with the supervision and conceptualization. JD, ÉF, PK, WZ, BF and AC contributed to the conception of MULTICHARME. The measurements in CHARME were performed by: JD, ÉF, JB, NH, FH and AC. JD, JB, RB, GD and $\mathrm{AC}$ contributed to the data curation. $\mathrm{AC}$ wrote the paper with 
some contributions from JD, FH, NH and CC. The figures were plotted by JD, JB, PK, BF and AC. All the authors contributed to the paper discussion and revision. AC, ÉF, GM and CC were involved in the funding acquisition.

Competing interests. The contact author has declared that neither they nor their co-authors have any competing interests.

Disclaimer. Publisher's note: Copernicus Publications remains neutral with regard to jurisdictional claims in published maps and institutional affiliations.

Acknowledgements. The LPCA towards CHARME is an associated partner of the ATMO-ACCESS European facility.

We are grateful to the logistics department of the Dunkirk University Management Center for their help in installing the MULTICHARME flanges. Marc Fourmentin is also thanked for his help in the graphical abstract conception.

This work was supported by the CaPPA project (Chemical and Physical Properties of the Atmosphere) funded by the French National Research Agency (ANR-11-LABX-0005-01) and the CLIMIBIO program supported by the Hauts-de-France Regional Council, the French Ministry of Higher Education and Research and the European Regional Development Fund. Jean Decker and Jonas Bruckhuisen were funded by CLIMIBIO and the Pôle Métropolitain de la Côte d'Opale, respectively. MULTICHARME was founded by the Research Quality Bonus of the University of Littoral Côte d'Opale, the Optics, Photonics, Applications Lasers (OPAL) network and the IRenE program.

Financial support. This research has been supported by the Agence Nationale de la Recherche (grant no. ANR-11-LABX-0005-01) and the Région Hauts-de-France (grant no. CPER CLIMIBIO).

Review statement. This paper was edited by Mingjin Tang and reviewed by two anonymous referees.

\section{References}

Barnes, I., Becker, K. H., and Mihalopoulos, N.: An FTIR product study of the photooxidation of dimethyl disulfide, J. Atmos. Chem., 18, 267-289, https://doi.org/10.1007/BF00696783, 1994.

Bigourd, D., Cuisset, A., Hindle, F., Matton, S., Fertein, E., Bocquet, R., and Mouret, G.: Detection and quantification of multiple molecular species in mainstream cigarette smoke by continuous-wave terahertz spectroscopy, Opt. Lett., 31, 23562358, https://doi.org/10.1364/OL.31.002356, 2006.

Bigourd, D., Cuisset, A., Hindle, F., Matton, S., Bocquet, R., Mouret, G., Cazier, F., Dewaele, D., and Nouali, H.: Multiple component analysis of cigarette smoke using $\mathrm{THz}$ spectroscopy, comparison with standard chemical analytical methods, Appl.
Phys. B, 86, 579-586, https://doi.org/10.1007/s00340-006-24954, 2007.

Birk, M., Wagner, G., and Flaud, J. M.: Experimental Linestrengths of Far-Infrared Pure Rotational Transitions of Ozone, J. Mol. Spectrosc., 163, 245-261, https://doi.org/10.1006/jmsp.1994.1021, 1994.

Bloss, C., Wagner, V., Jenkin, M. E., Volkamer, R., Bloss, W. J., Lee, J. D., Heard, D. E., Wirtz, K., Martin-Reviejo, M., Rea, G., Wenger, J. C., and Pilling, M. J.: Development of a detailed chemical mechanism (MCMv3.1) for the atmospheric oxidation of aromatic hydrocarbons, Atmos. Chem. Phys., 5, 641-664, https://doi.org/10.5194/acp-5-641-2005, 2005a.

Bloss, C., Wagner, V., Bonzanini, A., Jenkin, M. E., Wirtz, K., Martin-Reviejo, M., and Pilling, M. J.: Evaluation of detailed aromatic mechanisms (MCMv3 and MCMv3.1) against environmental chamber data, Atmos. Chem. Phys., 5, 623-639, https://doi.org/10.5194/acp-5-623-2005, 2005b.

Brubach, J., Manceron, L., Rouzières, M., Pirali, O., Balcon, D., Tchana, F. K., Boudon, V., Tudorie, M., Huet, T., Cuisset, A., and Roy, P.: Performance of the AILES THz-Infrared beamline at SOLEIL for High resolution spectroscopy, AIP Conf. Proc., 1214, 81-84, https://doi.org/10.1063/1.3326356, 2010.

Chernin, S. M.: Development of optical multipass matrix systems, J. Mod. Opt., 48, 619-632, https://doi.org/10.1080/09500340108230936, 2001.

Chernin, S. M. and Barskaya, E. G.: Optical multipass matrix systems, Appl. Opt., 30, 51-58, https://doi.org/10.1364/AO.30.000051, 1991.

Clerbaux, C., Boynard, A., Clarisse, L., George, M., Hadji-Lazaro, J., Herbin, H., Hurtmans, D., Pommier, M., Razavi, A., Turquety, S., Wespes, C., and Coheur, P.-F.: Monitoring of atmospheric composition using the thermal infrared IASI/MetOp sounder, Atmos. Chem. Phys., 9, 6041-6054, https://doi.org/10.5194/acp-96041-2009, 2009.

Colmont, J.-M., Bakri, B., Demaison, J., Mäder, H., Willaert, F., Tyuterev, V. G., and Barbe, A.: Microwave Fourier transform, millimeterwave, and submillimeterwave spectra of ozone in its vibrational ground state, J. Mol. Spectrosc., 2, 293-296, https://doi.org/10.1016/j.jms.2005.06.017, 2005.

Cuisset, A., Hindle, F., Mouret, G., Bocquet, R., Bruckhuisen, J., Decker, J., Pienkina, A., Bray, C., Fertein, É., and Boudon, V.: Terahertz Rotational Spectroscopy of Greenhouse Gases Using Long Interaction Pathlengths, Appl. Sci., 11, 1229, https://doi.org/10.3390/app11031229, 2021

De Lucia, F. C.: The submillimeter: A spectroscopist's view, J. Mol. Spectrosc., 261, 1-17, https://doi.org/10.1016/j.jms.2010.01.002, 2010.

EUROCHAMP 2020: https://www.eurochamp.org/publications/ guidelines-publishing, last access: 18 August 2021.

Fang, B., Yang, N., Wang, C., Zhao, W., Xu, X., Zhang, Y., and Zhang, W.: Detection of nitric oxide with Faraday rotation spectroscopy at $5.33 \mu \mathrm{m}$, Chin. J. Chem. Phys., 33, 37-42, https://doi.org/10.1063/1674-0068/cjcp1910182, 2020.

Fayad, L.: Characterization of the new atmospheric simulation chamber CHARME, and study of the ozonolysis reaction of a biogenic VOC, the $\gamma$-terpinene, $\mathrm{PhD}$ thesis, Earth Sciences, Université du Littoral Côte d'Opale, English, NNT: 2019DUNK0550, 2019. 
Fiedler, S. E., Hese, A., and Ruth, A. A.: Incoherent broad-band cavity-enhanced absorption spectroscopy, Chem. Phys. Lett., 371, 284-294, https://doi.org/10.1016/S0009-2614(03)00263-X, 2003.

Finlayson-Pitts, B. and Pitts Jr., J. P.: Chemistry of the Upper and Lower Atmosphere: Theory, Experiments, and Applications, Elsevier, 993 pp., https://doi.org/10.1016/B978-0-12257060-5.X5000-X, 1999.

Glowacki, D. R., Goddard, A., and Seakins, P. W.: Design and performance of a throughput-matched, zerogeometric-loss, modified three objective multipass matrix system for FTIR spectrometry, Appl. Opt., 46, 7872-7883, https://doi.org/10.1364/AO.46.007872, 2007a.

Glowacki, D. R., Goddard, A., Hemavibool, K., Malkin, T. L., Commane, R., Anderson, F., Bloss, W. J., Heard, D. E., Ingham, T., Pilling, M. J., and Seakins, P. W.: Design of and initial results from a Highly Instrumented Reactor for Atmospheric Chemistry (HIRAC), Atmos. Chem. Phys., 7, 53715390, https://doi.org/10.5194/acp-7-5371-2007, 2007b.

Gordon, I. E., Rothman, L. S., Hargreaves, R. J., Hashemi, R., Karlovets, E. V., Skinner, F. M., Conway, E. K., Hill, C., Kochanov, R. V., Tan, Y., Wcisło, P., Finenko, A. A., Nelson, K., Bernath, P. F., Birk, M., Boudon, V., Campargue, A., Chance, K. V., Coustenis, A., Drouin, B. J., Flaud, J.-M., Gamache, R. R., Hodges, J. T., Jacquemart, D., Mlawer, E. J., Nikitin, A. V., Perevalov, V. I., Rotger, M., Tennyson, J., Toon, G. C., Tran, H., Tyuterev, V. G., Adkins, E. M., Baker, A., Barbe, A., Canè, E., Császár, A. G., Dudaryonok, A., Egorov, O., Fleisher, A. J., Fleurbaey, H., Foltynowicz, A., Furtenbacher, T., Harrison, J. J., Hartmann, J.-M., Horneman, V.-M., Huang, X., Karman, T., Karns, J., Kassi, S., Kleiner, I., Kofman, V., Kwabia-Tchana, F., Lavrentieva, N. N., Lee, T. J., Long, D. A., Lukashevskaya, A. A., Lyulin, O. M., Makhnev, V. Yu., Matt, W., Massie, S. T., Melosso, M., Mikhailenko, S. N., Mondelain, D., Müller, H. S. P., Naumenko, O. V., Perrin, A., Polyansky, O. L., Raddaoui, E., Raston, P. L., Reed, Z. D., Rey, M., Richard, C., Tóbiás, R., Sadiek, I., Schwenke, D. W., Starikova, E., Sung, K., Tamassia, F., Tashkun, S. A., Vander Auwera, J., Vasilenko, I. A., Vigasin, A. A., Villanueva, G. L., Vispoel, B., Wagner, G., Yachmenev, A., and Yurchenko, S. N.: The HITRAN2020 molecular spectroscopic database, J. Quant. Spectrosc. Radiat. Transf., 277, 107949, https://doi.org/10.1016/j.jqsrt.2021.107949, 2022.

Harris, S. J., Liisberg, J., Xia, L., Wei, J., Zeyer, K., Yu, L., Barthel, M., Wolf, B., Kelly, B. F. J., Cendón, D. I., Blunier, T., Six, J., and Mohn, J.: $\mathrm{N}_{2} \mathrm{O}$ isotopocule measurements using laser spectroscopy: analyzer characterization and intercomparison, Atmos. Meas. Tech., 13, 2797-2831, https://doi.org/10.5194/amt13-2797-2020, 2020.

Hindle, F., Kuuliala, L., Mouelhi, M., Cuisset, A., Bray, C., Vanwolleghem, M., Devlieghere, F., Mouret, G., and Bocquet, R.: Monitoring of food spoilage by high resolution $\mathrm{THz}$ analysis, Analyst, 143, 5536-5544, https://doi.org/10.1039/C8AN01180J, 2018.

Hindle, F., Bocquet, R., Pienkina, A., Cuisset, A., and Mouret, G.: Terahertz gas phase spectroscopy using a high-finesse Fabry-Pérot cavity, Optica, 6, 1449, https://doi.org/10.1364/OPTICA.6.001449, 2019.

Hoor, P. M., Fischer, H., Wong, S., Engel, A., and Wetter, T.: Intercomparison of airborne $\mathrm{N}_{2} \mathrm{O}$ measurements using tunable diode laser absorption spectroscopy and in situ gas chromatography, SPIE's International Symposium on Optical Science, Engineering, and Instrumentation, 25 October 1999, Denver, CO, USA, 109-115, https://doi.org/10.1117/12.366442, 1999.

Itoh, H., Suzuki, T., Suzuki, S., and Rusinov, I. M.: Investigation of Ozone Loss Rate Influenced by the Surface Material of a Discharge Chamber, Ozone Sci. Eng., 26, 487-497, https://doi.org/10.1080/01919510490507847, 2004.

Itoh, H., Isegame, S., Miura, H., Suzuki, S., and Rusinov, I. M.: Surface Loss Rate of Ozone in a Cylindrical Tube, Ozone Sci. Eng., 33, 106-113, https://doi.org/10.1080/01919512.2011.548295, 2011.

Kwabia Tchana, F., Willaert, F., Landsheere, X., Flaud, J.-M., Lago, L., Chapuis, M., Herbeaux, C., Roy, P., and Manceron, L.: A new, low temperature long-pass cell for mid-infrared to terahertz spectroscopy and synchrotron radiation use, Rev. Sci. Instrum., 84, 093101, https://doi.org/10.1063/1.4819066, 2013.

Lou, M., Swearer, D. F., Gottheim, S., Phillips, D. J., Simmons, J. G., Halas, N. J., and Everitt, H. O.: Quantitative analysis of gas phase molecular constituents using frequencymodulated rotational spectroscopy, Rev. Sci. Instrum., 90, 053110, https://doi.org/10.1063/1.5093912, 2019.

Massabò, D., Danelli, S. G., Brotto, P., Comite, A., Costa, C., Di Cesare, A., Doussin, J. F., Ferraro, F., Formenti, P., Gatta, E., Negretti, L., Oliva, M., Parodi, F., Vezzulli, L., and Prati, P.: ChAMBRe: a new atmospheric simulation chamber for aerosol modelling and bio-aerosol research, Atmos. Meas. Tech., 11, 58855900, https://doi.org/10.5194/amt-11-5885-2018, 2018.

Meng, L., Wang, G., Augustin, P., Fourmentin, M., Gou, Q., Fertein, E., Ba, T. N., Coeur, C., Tomas, A., and Chen, W.: Incoherent broadband cavity enhanced absorption spectroscopy (IBBCEAS)-based strategy for direct measurement of aerosol extinction in a lidar blind zone, Opt. Lett., 45, 1611-1614, https://doi.org/10.1364/OL.389093, 2020.

Mouret, G., Guinet, M., Cuisset, A., Croize, L., Eliet, S., Bocquet, R., and Hindle, F.: Versatile Sub-THz Spectrometer for Trace Gas Analysis, IEEE Sens. J., 13, 133-138, https://doi.org/10.1109/JSEN.2012.2227055, 2013.

Omar, A., Eliet, S., Cuisset, A., Dhont, G., Coeur-Tourneur, C., Bocquet, R., Mouret, G., and Hindle, F.: Continuous Monitoring of Formaldehyde Photolysis Products by $\mathrm{THz}$ Spectroscopy, IEEE Sens. J., 15, 6141-6146, https://doi.org/10.1109/JSEN.2015.2453271, 2015.

Pickett, H. M., Poynter, R. L., Cohen, E. A., Delitsky, M. L., Pearson, J. C., and Müller, H. S. P.: Submillimeter, Millimeter, And Microwave Spectral Line Catalog, J. Quant. Spectrosc. Radiat. Transf., 60, 883-890, https://doi.org/10.1016/S00224073(98)00091-0, 1998.

Ravishankara, A. R., Daniel, J. S., and Portmann, R. W.: Nitrous Oxide $\left(\mathrm{N}_{2} \mathrm{O}\right)$ : The Dominant Ozone-Depleting Substance Emitted in the 21st Century, Science, 326, 123-125, https://doi.org/10.1126/science.1176985, 2009.

Ren, Y., Grosselin, B., Daële, V., and Mellouki, A.: Investigation of the reaction of ozone with isoprene, methacrolein and methyl vinyl ketone using the HELIOS chamber, Faraday Discuss., 200, 289-311, https://doi.org/10.1039/C7FD00014F, 2017.

Röckmann, T., Kaiser, J., Crowley, J. N., Brenninkmeijer, C. A. M., and Crutzen, P. J.: The origin of the anomalous or "mass-independent" oxygen isotope fractionation 
in tropospheric $\mathrm{N}_{2} \mathrm{O}$, Geophys. Res. Lett., 28, 503-506, https://doi.org/10.1029/2000GL012295, 2001.

Rohart, F., Colmont, J.-M., Wlodarczak, G., and Bouanich, J.P.: $\mathrm{N}_{2}$ - and $\mathrm{O}_{2}$-broadening coefficients and profiles for millimeter lines of ${ }^{14} \mathrm{~N}_{2} \mathrm{O}$, J. Mol. Spectrosc., 222, 159-171, https://doi.org/10.1016/S0022-2852(03)00220-0, 2003.

Rohrer, F., Bohn, B., Brauers, T., Brüning, D., Johnen, F.-J., Wahner, A., and Kleffmann, J.: Characterisation of the photolytic HONO-source in the atmosphere simulation chamber SAPHIR, Atmos. Chem. Phys., 5, 2189-2201, https://doi.org/10.5194/acp5-2189-2005, 2005.

Roucou, A., Fontanari, D., Dhont, G., Jabri, A., Bray, C., Hindle, F., Mouret, G., Bocquet, R., and Cuisset, A.: Full Conformational Landscape of 3-Methoxyphenol Revealed by Room Temperature mm-wave Rotational Spectroscopy Supported by Quantum Chemical Calculations, ChemPhysChem, 19, 1572-1578, https://doi.org/10.1002/cphc.201800148, 2018.

Roucou, A., Goubet, M., Kleiner, I., Bteich, S., and Cuisset, A.: Large Amplitude Torsions in Nitrotoluene Isomers Studied by Rotational Spectroscopy and Quantum Chemistry Calculations, ChemPhysChem, 21, 2523-2538, https://doi.org/10.1002/cphc.202000591, 2020.

Sigrist, M. W. (Ed.): Air monitoring by spectroscopic techniques, chap. 5, Wiley, New York, 241-243, ISBN 978-0-471-55875-0, 1994.
Wagner, R., Bunz, H., Linke, C., Möhler, O., Naumann, K.-H., Saathoff, H., Schnaiter, M., and Schurath, U.: Chamber Simulations of Cloud Chemistry: The AIDA Chamber, in: Environmental Simulation Chambers: Application to Atmospheric Chemical Processes, Dordrecht, 67-82, https://doi.org/10.1007/1-40204232-9_5, 2006.

Wang, J., Doussin, J. F., Perrier, S., Perraudin, E., Katrib, Y., Pangui, E., and Picquet-Varrault, B.: Design of a new multi-phase experimental simulation chamber for atmospheric photosmog, aerosol and cloud chemistry research, Atmos. Meas. Tech., 4, 2465-2494, https://doi.org/10.5194/amt-4-2465-2011, 2011.

Wang, W., Wang, Z., and Duan, Y.: Performance evaluation of THz Atmospheric Limb Sounder (TALIS) of China, Atmos. Meas. Tech., 13, 13-38, https://doi.org/10.5194/amt-13-13-2020, 2020.

White, J. U.: Long Optical Paths of Large Aperture, J. Opt. Soc. Am., 32, 285-288, https://doi.org/10.1364/JOSA.32.000285, 1942.

Williams, E.: Gaussian Beam Propagation, LightMachinery Inc., https://lightmachinery.com/optical-design-center/ more-optical-design-tools/gaussian-beam-propagation/, last access: 29 August 2019.

Wu, T., Coeur-Tourneur, C., Dhont, G., Cassez, A., Fertein, E., He, X., and Chen, W.: Simultaneous monitoring of temporal profiles of $\mathrm{NO}_{3}, \mathrm{NO}_{2}$ and $\mathrm{O}_{3}$ by incoherent broadband cavity enhanced absorption spectroscopy for atmospheric applications, J. Quant. Spectrosc. Radiat. Transf., 133, 199-205, https://doi.org/10.1016/j.jqsrt.2013.08.002, 2014. 